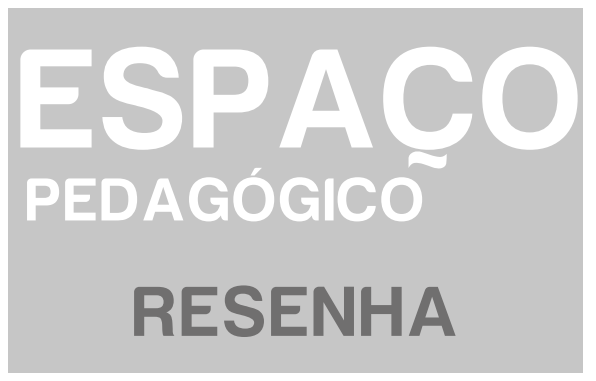




\section{Avaliar para melhor colaborar, colaborar para melhor avaliar: resenha da obra "Evaluating collaboration networks in higher education research: drivers of excellence"}

Bernardo Sfredo Miorando*

A obra Evaluating collaboration networks in higher education research: drivers of excellence, de autoria de Denise Leite e Isabel Pinho, foi publicada pela Palgrave em 2017. O título pode ser traduzido livremente como "Avaliando redes de colaboração na pesquisa em educação superior: fios condutores da excelência". Colaboramos, Cláudia Pinho e eu, com a organização dos originais desta obra.

Em um momento histórico em que a ideia de uma excelência individualista e competitiva é acionada para compor hegemonias no campo científico, as autoras chamam atenção para a importância de a pesquisa sobre educação superior se voltar para um fenômeno nuclear do campo acadêmico: a colaboração, agora armada em redes muitas vezes internacionais. Esse propósito é afirmado desde a dedicatória do livro, oferecido à memória do saudoso professor Rui Santiago. Lembram as autoras: "[...] com ele, nós construímos redes através do Atlântico" (LEITE; PINHO, 2017, p. [vi]).

E foi por intermédio de Rui que as autoras se conectaram, possibilitando assim a cooperação transatlântica consubstanciada nesse livro. Denise Leite, pesquisadora do Conselho Nacional de Desenvolvimento Científico e Tecnológico (CNPq) e docente do Programa de Pós-Graduação em Educação da Universidade Federal do Rio Grande do Sul (Ufrgs), no Brasil, vem desdobrando seus estudos sobre avaliação institucional e inovação pedagógica sobre o objeto das redes de colaboração em pesquisa. Esse mesmo objeto faz parte do escopo das investigações na área da gestão do conhecimento realizadas por Isabel Pinho, membro do Centro de Investigação de Políticas de Educação Superior (Cipes) e pesquisadora da Unidade de Investigação em Governança, Competitividade e Políticas Públicas (Govcopp) da Universidade de Aveiro, em Portugal. Encontraram-se, então, na consecução do projeto de pesquisa “Avaliação e Redes de Colaboração", financiado pelo CNPq,

Recebido em 09/07/2018 - Aprovado em 03/10/2018

http://dx.doi.org/10.5335/rep.v25i3.8627

Doutorando em Educação pela Universidade Federal do Rio Grande do Sul (UFRGS). Mestre em Educação (2014) pela UFGRS. Membro do Grupo de Pesquisa Inovação e Avaliação na Universidade (InovAval). E-mail: bernardo.sfredo@ ufrgs.br 
coordenado por Denise e desenvolvido no espaço-tempo do grupo de pesquisa Inovação e Avaliação na Universidade (InovAval). É importante destacar esses elementos, pois, como apontam as autoras, todos eles são importantes na articulação de uma rede de pesquisa colaborativa: as trajetórias individuais, as inserções institucionais, os interesses temáticos, os projetos, os mecanismos de financiamento. Todos eles se combinam nas estratégias e práticas - dotadas de uma pedagogia específica - pelas quais se estruturam redes de colaboração, muitas vezes apoiadas ou abrigadas em grupos de pesquisa.

A obra contém sete capítulos que funcionam como textos independentes, cada qual apresentando seus resumos, suas notas e suas referências. Isso faz com que a leitora ou o leitor - trabalhando nos processos de ensino, pesquisa e extensão, ou gerindo políticas públicas ou institucionais - possa ler a obra inteira como texto integral e destacar trechos para a discussão com seus grupos de colaboradores. Para aquelas e aqueles inseridos no sistema da pesquisa acadêmica brasileira, é interessante informar que o livro está acessível por meio do sistema Periódicos Capes. ${ }^{1}$

O primeiro capítulo do livro é dedicado à discussão sobre a geografia da ciência e a colaboração internacional em pesquisa. As autoras chamam a atenção para a necessidade de políticas de avaliação reconhecerem a ciência como um fenômeno social: o uso de medidas uniformes não leva em consideração os diferentes perfis apresentados pelas disciplinas, pelas regiões do mundo, como também as diferentes formas de combinação de áreas de conhecimento na composição de perfis regionais de atividade científica. A busca da excelência nas dinâmicas científicas passa pelo estabelecimento de colaborações internacionais, de modo a disseminar avanços, fazer fluir o conhecimento de fronteira e ampliar sua capacidade de absorção pelos sistemas nacionais de pesquisa.

O segundo capítulo trata de limites e fronteiras à colaboração internacional. Em termos da elaboração simbólica, a fronteira estaria na necessidade de sistematizar novos conhecimentos que deem sustentação a habilidades de liderança de grupos de pesquisa e redes colaborativas, considerando especialmente as barreiras da linguagem e do hiato entre diferentes práticas de publicação e culturas de expressão escrita. Em termos dos limites da realidade material, a divisão internacional do trabalho classificaria também os países em termos de seu patamar relativo de desenvolvimento, condicionando os papéis que podem desempenhar na produção científica: o Sul, periférico, estaria relegado ao fornecimento de dados e ao consumo do conhecimento processado pelo Norte, central, que teria poder sobre a formulação das agendas teóricas e também sobre os canais de comunicação científica. 
O terceiro capítulo apresenta abordagens teóricas às redes de colaboração em pesquisa. As autoras buscam contribuir para o entendimento do fenômeno combinando a emergente "nova ciência das redes" a elementos clássicos dos fundamentos da educação. De um lado, mobilizam-se teorias das redes sociais e sua análise para caracterizar os componentes de redes de colaboração em pesquisa e seus ciclos de vida. De outro, a sociologia e a psicologia são acionadas para entender o que leva os indivíduos a entrar e permanecer nas redes. São ainda apresentados tipos de colaboração e padrões de confiança - fator encarado como fundamental à formação e à manutenção de conexões interpessoais.

$\mathrm{O}$ quarto capítulo interroga o que os pesquisadores dizem e o que as redes mostram sobre colaboração em pesquisa. As respostas são buscadas em dados empíricos coletados junto a lideranças de grupos de pesquisa no Brasil e em Portugal, abordando tanto aqueles com redes consolidadas, sediados em universidades prestigiosas, quanto aqueles que se projetam desde uma jovem universidade brasileira. Chama-se atenção para como as fronteiras disciplinares demarcam distintas práticas de coautoria e publicação. A partir do estudo de caso de uma rede específica associada a um grupo de pesquisa, apresentam-se constatações sobre grupos e redes de pesquisa, indicando diferenciações analíticas em relação a ambos os objetos.

O quinto capítulo questiona o que se mede ao avaliar redes de colaboração em pesquisa. Expõe-se o uso difundido das técnicas bibliométricas tradicionais em processos avaliativos e rankings, apresentando outras possibilidades a partir do emprego da altmetria. As autoras tensionam o uso da cienciometria, assinalando que, para além do foco na produtividade pela contabilização de produtos, outros indicadores podem ser usados para captar processos colaborativos. Assim, manejando ferramentas emergentes no cenário da ciência internacional, seria possível passar da verificação de performances individuais, agregadas ou não, ao fomento de inovações no trabalho em parceria.

O sexto capítulo propõe Research Networks Participatory Evaluation (RNPE), ou seja, um modelo para a avaliação participativa de redes de pesquisa. A partir de um apanhado histórico das práticas avaliativas em educação, entendendo que, quando se trata de avaliar redes de pesquisa, são necessárias adaptações aos contextos histórico e geográfico nos quais a pesquisa se desenvolve. Assim, a RNPE se dedica a avaliar o processo colaborativo, medindo a intensidade e as modalidades da colaboração em coautorias e aferindo caracteres estruturantes de interação entre pesquisadores - fatores que constituem os laços pelos quais as redes se armam. As autoras propõem uma série de indicadores quantitativos e qualitativos, pondo o acento da avaliação no nível micro, de modo a atentar para o caráter ético e pedagógico do trabalho em rede na formação de novos pesquisadores. 
O sétimo capítulo apresenta considerações finais sobre os papéis da avaliação e da colaboração na produção do conhecimento. Na revisão dos argumentos, as autoras reafirmam o componente emancipatório da avaliação participativa, como canal para o empoderamento dos atores no processo de produção de conhecimento. Os fatores propulsores da RNPE - a dinâmica coletiva da rede e a centralidade da colaboração para a atividade de pesquisa - se apresentam como ponto de apoio desde os quais questionar a própria avaliação de produtividade que vem sendo praticada. Se, de modo geral e hegemônico, a ciência internacional segue sendo hierárquica, as possibilidades de horizontalidade no desenvolvimento das redes podem conter elementos de democratização do conhecimento.

A obra representa, assim, uma contribuição para a interdisciplinar área internacional de estudos sobre educação superior com uma visão que não é a dos países ou das disciplinas centrais, ainda que dialogue com os conhecimentos produzidos nesses contextos. Em termos de posicionalidade, é interessante observar que as autoras escrevem de países que estão no centro da periferia - no caso do Brasil - e na periferia do centro - no caso de Portugal -, buscando viabilizar um posicionamento favorável ao seu desenvolvimento nacional na geopolítica da ciência global.

Leitoras e leitores do Brasil podem encontrar no livro inspiração para revisitar seu fazer científico, preparando-se para potencializar novas iniciativas pelo estabelecimento de parcerias. Especialmente em um contexto de desestruturação da atividade científica, de desinvestimento na pesquisa e de desconstituição da parca experiência democrática de nosso país, é possível encontrar na obra elementos que informem o caráter ético da investigação colaborativa e da formação de pesquisadores. A avaliação e a colaboração, usadas tantas vezes para ranquear, reforçar fronteiras e reificar desigualdades, são colocadas a serviço de outros propósitos. Trata-se de avaliar para melhor colaborar e colaborar para melhor avaliar.

\section{Nota}

1 A partir de uma conexão com internet protocol (IP) identificado às instituições participantes do sistema, acessa-se o portal Springer Link, da companhia Springer, que detém a editora Palgrave Macmillan, e se pode baixar o livro. A obra está disponível no endereço: <https://link.springer.com/book/10.1007\% 2F978-3-319-45225-8>. Para mais informações sobre o portal Periódicos Capes, acessar a seção de Perguntas Frequentes em: <http://www.periodicos.capes.gov.br/index.php?option=com_pfaq\&Itemid=96\&>.

\section{Referência}

LEITE, Denise; PINHO, Isabel. Evaluating collaboration networks in higher education research: drivers of excellence. Cham: Palgrave Macmillan, 2017. 